\title{
To adjust and endure: a qualitative study of symptom burden in older people with multimorbidity
}

Jeanette Eckerblad, Kersti Theander, Anne Ekdahl, Tiny Jaarsma and Iingrid Hellström

\section{Linköping University Post Print}

\section{Tweet}

N.B.: When citing this work, cite the original article.

Original Publication:

Jeanette Eckerblad, Kersti Theander, Anne Ekdahl, Tiny Jaarsma and Iingrid Hellström, To adjust and endure: a qualitative study of symptom burden in older people with multimorbidity, 2015, Applied Nursing Research, (28), 4, 322-327.

http://dx.doi.org/10.1016/j.apnr.2015.03.008

Copyright: WB Saunders

http://www.elsevier.com/

Postprint available at: Linköping University Electronic Press

http://urn.kb.se/resolve?urn=urn:nbn:se:liu:diva-122740 
To adjust and endure: A qualitative study of symptom burden in older people with multimorbidity

${ }^{1}$ Eckerblad J, RN., ${ }^{2}$ Theander K, RN, PhD., ${ }^{3,4}$ Ekdahl A, MD, PhD., ${ }^{1}$ Jaarsma T, RN, PhD., ${ }^{1,5}$ Hellstrom I, RN, PhD.

${ }^{1}$ Department of Social and Welfare Studies, Faculty of Health Sciences, Linkoping

University, Linkoping, Sweden

${ }^{2}$ Faculty of Health, Science and Technology, Department of Health

Sciences, Nursing,

Karlstad University, Karlstad, Sweden,

${ }^{3}$ Department of Geriatric Medicine and Department of Social and

Welfare Studies,

Linköping University, Linköping, Sweden.

${ }^{4}$ Division of Clinical Geriatrics, Department of Neurobiology, Care

Sciences and

Society (NVS), Karolinska Institutet, Stockholm, Sweden

${ }^{5}$ Ersta Skondal University College, Stockholm, Sweden

Corresponding author: Jeanette Eckerblad

Mail to: Jeanette.eckerblad@liu.se

Linkoping University / ISV

60174 Norrkoping

Phone: + 4611363575 


\section{Abstract}

Context. Older people with multimorbidity are vulnerable and often suffer from conditions that produce a multiplicity of symptoms and a reduced health-related quality of life.

Objectives. The aim of this study is to explore the experience of living with a high symptom burden from the perspective of older community-dwelling people with multi-morbidity.

Method. A qualitative descriptive design with semi-structured interviews, including 20 community-dwelling older people with multi-morbidity and a high symptom burden. The participants were 79-89 years old with a mean of 12 symptoms per person. Data were analyzed using content analyses.

Results. The experience of living with a high symptom burden revealed the overall theme, "To adjust and endure" and three sub-themes. The first subtheme was "To feel inadequate and limited". Participants reported they no longer had the capacity or the ability to manage and they felt limited and isolated from friends or family. The second sub-theme was "To feel dependent". This was a new and inconvenient experience, the burden they put on others caused a feeling of guilt. The final sub-theme was "To feel dejected". The strength to manage and control their conditions was gone, the only thing left to do was to sit or lie down and wait for it all to pass.

Conclusion. This study highlights the importance of a holistic approach when taking care of older people with multi-morbidity. This approach should employ a broad symptom assessment to reveal diseases and conditions that it is possible to treat or improve.

Key words: Multimorbidity, older people, symptom burden, content analysis. 


\section{Introduction}

Chronic diseases tend to increase with old age, and approximately $70 \%$ of people aged above 80 years have been reported to suffer from multi-morbidity (Boeckxstaens and De Graaf 2011). For community-dwelling older people with chronic diseases life is filled with challenges as they try to manage everyday life and cope with symptoms of different origins. Multi-morbidity is a condition that may cause loss of autonomy, disability, social isolation (Falk et al. 2013) and frailty (Le Reste et al. 2013) if the diseases are not well managed. Even so, research has shown that older people tend to report fewer symptoms compared to younger people (Goldberg et al. 2010). It might be because it is more difficult for older people to detect and interpret symptoms (Riegel et al. 2010), or that older people might fail to recognize and report significance changes in health status as a result of the new signs or symptoms being covered by other chronic diseases (Bender 1992). Older people with symptoms that are well managed are more likely to feel safe, in control and to experience good health (Ebrahimi et al. 2013). A challenge for the health care system is to organize and provide care that is individualized and that focuses on the whole person rather than on separate health issues (McEvoy and Duffy 2008). A holistic approach could help researchers and clinicians to identify resources and barriers relevant to the management of similar and unique symptoms that cause problems in the everyday lives of older community-dwelling people with multi-morbidity. 
Older people with advanced chronic diseases are known to suffer from symptoms such as pain, lack of energy/fatigue, shortness of breath and loss of appetite (Walke et al. 2006, Wajnberg et al. 2013). However, the way a symptom is perceived is a unique experience and a lack of symptom control may result in significant deterioration of health-related quality of life (Newcomb 2010). Symptom burden is defined as "the subjective, quantifiable prevalence, frequency, and severity of symptoms placing a physiologic burden on patients and producing multiple negative, physical, and emotional patient responses" (Gapstur 2007). Symptom burden is often used to describe the sum of symptom scores or the mean number of symptoms per person (Gill et al. 2012), and could serve as a sensitive target for intervention, particularly to improve outcomes related to quality of life in older people (Sheppard et al. 2013). However, there is no consensus on what level indicates a severe or a very severe symptom burden, nor on the experience and impact of symptom scores (Gill et al. 2012). The experiences of symptom burden in community-dwelling older people with chronic diseases have been reported by use of different symptom assessment scales (Eckerblad et al. 2015)' (Walke et al. 2006, Salanitro et al. 2012), but subjective descriptions of the older people's own experiences are scarce (Gill et al. 2012). Therefore, the aim of this study is to explore the experience of living with a high symptom burden from the perspective of older community-dwelling people with multi-morbidity. 


\section{Method}

\section{Design}

A qualitative study based on semi-structured interviews with 20 older people with multi-morbidity, was performed by using content analysis. The participants in this study were recruited from a prospective single center randomized controlled trial with 382 older people (Mazya et al. 2013). The study followed the ethical guidelines given in the Declaration of Helsinki and was approved by the Linkoping local ethical Committee (Dnr 2012/244-32).

\section{Participants and procedure}

We sought a purposive sample with participants that reported high scores on the Memorial Symptom Assessment Scale (MSAS) (Portenoy et al. 1994) after the second year follow-up in the Age-Fit study (Mazya et al. 2013). In this study, a high score on the MSAS equaled $\geq 3$ on frequency, severity or distress in at least four prevalent symptoms. The total symptom burden score (TMSAS) was the average score of all 32 symptoms in the MSAS instrument (Zambroski et al. 2005). An information letter explaining the purpose of this study was sent to the participants who fulfilled the inclusion criteria. People who were willing were offered an appointment at their home for an interview. Sixteen women and four men were included in this study and they had a mean age of $84( \pm 2.9)$. The participants suffered from a high symptom load with a mean of $12( \pm 5.3)$ prevalent symptoms per person as well as a high total symptom burden score median (range) $0.96(0.31-2.27)$ (Table 1$)$. 


\section{Interviews}

The MSAS protocol from the second year follow-up was used to guide the interviews with additional open-ended questions. The first interview was performed by the first author (JE) as a pilot and the transcription of this first interview was peer-reviewed by the last author ( $\mathrm{I} \mathrm{H}$ ). No changes in the interview guide were made and the first interview is therefore included in the analysis. The participants were asked the following questions: What does the symptom feel like? -When does it bother you the most? -What is it like living your life with many co-occurring symptoms? -What consequences does it have? -In what way does this affect your life? All interviews were performed by the first author (JE) between March and September 2013. The interviews were audiorecorded and transcribed, and confidentiality was provided by giving each interview transcript a code number. The interviews ranged between 20-55 minutes. In total, each visit lasted approximately two hours, including small talk.

\section{Analysis}

\section{Content analysis}

The transcribed interviews were analyzed using qualitative content analysis (Graneheim and Lundman 2004). Content analysis is a suitable method for analyzing sensitive phenomena and has come into wide use in health studies (Hsieh and Shannon 2005). An advantage is that larger volumes of textual data and different textual sources can be dealt with at the same time (Elo and Kyngas 
2008). The analysis was inductive and resulted in themes (Graneheim and Lundman 2004).

1. The transcribed interviews were read thorough several times to get a deeper understanding of the whole with a focus both on the surface structure of the text and the underlying meaning.

2. Significant text units (meaning units) were identified, marked, and labeled with open coding close to the participant's own statements (Table 2).

3. Codes were then sorted and grouped into sub-themes depending on the content.

4. During the analysis the sub-themes were grouped and re-grouped to identify significant similarities and differences, and two sub-themes were merged into one.

5. The final structure consisted of three sub-themes and one overall theme (figure 1). 


\section{Findings}

\section{To adjust or endure}

To adjust or endure was interpreted as the overall theme in this study. Living your life with a high symptom burden was described by the participants as an endless struggle where you either had to adjust or endure to the current situation since they did not see any other option.

Participant (P); It takes time getting used to being old, and I believe that people who have always been physically active will face a more drastic change. It's like a sort of resignation. It is what it is, and I think you have to adjust to it.

Interviewer (I); Do you have any strategies for dealing with this?

P; No, this is how it is now and there is nothing I can do. Maybe I can choose one of the things I want to do and just push the other things aside. But that makes you feel bad about yourself. But you know there are so many ailments hindering me.

(Participant 14. An 81-year-old woman who lived alone).

Living with a high symptom burden had an effect on their body and soul. One participant described it as "It is like my body and mind are not connected anymore and it is just awful". Their bodies were failing and the life they were used to was gone forever. The majority of the participants also said that their fighting spirit or the will to take charge of their situation now was gone. The main theme of this study was composed of three sub-themes; to feel inadequate and limited, to feel dependent, and to feel dejected. 


\section{To feel inadequate and limited}

The participants felt that they no longer had either the capacity or the ability to manage or control things. Things they had done with ease before were just not possible anymore since they described their bodies as "totally worn out" and they felt useless.

Interviewer (I); It says here (referring to MSAS score of the patients) that you do not recognize yourself anymore?

Participant (P); Yes, I used to be a lot more active. Now I have a sort of a more vegetative life where I just try to make it through day by day.

\section{I; How would you say that you deal with all these issues?}

P; I think I have kind of survived myself. I am looking forward to and hope that I could get on my feet again and at least be able to help out a little bit. Then I would be better. But as it is, I alas find no great zest for life.

(Participant 7; An 89-year-old man that lived with his wife)

Not only was the physical capacity failing; participants also said that their cognitive capacity was affected, e.g. before the high symptom burden developed one of the participants read four newspapers each morning, but now he could not even go through one. Not having the strength to keep up to date with what was happening in world around them led to feelings of being inadequate. The psychological effects of living with a high symptom burden caused an emotional vulnerability. Feeling worried, nervous or sad made it hard to sleep and some reported problems of being so emotional and easily moved that they could suddenly start crying in an uncontrolled manner. The participants did not recognize or feel like themselves anymore; they missed the person they had once 
been. The participants had become limited in their choice of activities, and a consequence of the limitations was that they often felt isolated from friends and family and even their partner. Some said that they now had a rather meaningless existence in which they were limited to just sitting and doing nothing. They felt their life was being taken from them bit by bit, and it was often the lack of energy they saw as the cause of the limitation. Sometimes, they chose to stay at home, not because they could not manage to leave home but because they knew they would slow everyone else down. Another possible reason for choosing to stay at home was that they could not maintain the good spirits they thought they needed to have around other people, or that they would be so totally exhausted for a long time after the event and it just was not worth it. Feeling inadequate in so many ways led to a rather limited and isolated life. However, there was a variation in the description of what "being limited" was. Some participants spoke of their life being limited by the fact that they could not drive their car anymore. Other participants spoke of their desire to be able to go for a walk outside, and some to just be able to move inside their apartment by themselves. The limitations were sometimes caused by the loss of their partner, forcing them to now live by themselves and having no one to lean on. The limitations made the participants incapable of performing necessary chores around the house, which for the first time made them dependent upon others. 


\section{To feel dependent}

The participants could no longer manage things they did prior to the development of their high symptom burden. To be dependent on others to provide services was a new and inconvenient experience. This dependency was out of their control and there was nothing they could do to change it. The help they received came from partners, family or home-care services.

Interviewer (I); You get riled up you say, what consequences does that entail?

Participant (P); I don't feel well. When I get carried away and stressed out. I get unfocused and I don't know how to deal with all of this. I try to stay calm and remind myself not to put too much pressure on myself. It is not easy to get old and re-evaluate yourself, especially when you're not healthy. I have so many aches and pains, and I have so much medication, there's so much I wish I could do but I can't. So I have to ask for help, I have never asked for help before. (Participant 14. An 81-year-old woman who lived alone).

Most of the participants lived alone, but among the ones that still lived with their partner this dependency and the guilt it caused seemed to hit even harder; all the chores that they considered to be "their" responsibility now had to be performed by their partner. The dependency caused much guilt, especially when it came to partners or children, since the partner often had health issues themselves and the children were often busy with work and children of their own. Not being able to manage on their own was often seen as a sign of weakness and the participants sometimes made jokes about it "You know I have just become lazy in old age" was quite a common expression. To be able to live on your own and manage by yourself was important to preserve the sense of self. All were dependent on 
support in one way or another from health care. Different diseases resulted in visits to several different health care departments for checkups. Even though they knew they ought to go and felt guilty about not doing so, the effort to plan transportation and wait their turn in line just took too much energy.

\section{To feel dejected}

The participants said that it was hard to manage all the co-occurring symptoms. Some had given up hope and did not have the strength to try anymore. "In this old age you shouldn't expect so much out of life anyway", some said. A few said that they had lost their will to live. When the burden was too high the only thing left to do was to sit or lie down and wait for it to pass. The participants described a feeling of being unimaginably tired. The lack of energy was always present but there were periods when it was even worse and there was just no way to handle it.

Interviewer (I); So, you sleep long into the morning. When you wake up, do you feel rested?

Participant (P); No I'm just as tired. I am more tired in the mornings than I am during the evenings when I go to bed.

I; This tiredness, is it something that you can affect in some way?

P; No my body is finished.

I; What causes this constant tiredness?

P; Age I would assume, and ailments. It has to take its toll somewhere. I am one of those with multimorbidity you know. (Participant 5. An 85-year-old woman who lived alone)

These episodes could come and go, often without any notice and while they lasted the subjects could not do anything about them but let them run their course. The fear of these episodes had made some of them so scared that they 
stopped taking walks outside or going out to meet friends. Even with the high symptom burden a common statement from the participants was "Well you should not complain", because there was always someone who had it worse.

\section{Discussion and Recommendations}

This study sheds light on the experience of older people with multi-morbidity living with a high symptom burden. To adjust and endure were interpreted as the main theme in this study where the participants described that living everyday life with many co-occurring symptoms was hard to manage. The participants often referred to their old age as a source of their high symptom burden rather than their many diseases. Similar findings were found in another qualitative study with people with multi-morbidity aged over 80 , where participants blamed their increasing variety of health problems such as pains, sleepiness and problems with balance, mobility, eyesight, hearing and memory loss on the deterioration of their body due to old age (Elias and Lowton 2014). It can sometimes be difficult to draw a sharp line between normal ageing and diseases (Larsson and Thorslund 2006; 67) but symptoms and disease should not be considered a normal part of aging (Stewart et al. 2012). A stereotypical belief that 'old age causes illness' has been shown to be associated with negative health outcomes for older people, and this way of thinking is unfortunately often reinforced by health care professionals (Stewart et al. 2012, Cameron et al.). 
The participants said that symptom burden affected their capacity in a physical, psychological and cognitive way and made them feel inadequate and limited, and dependent on others for support. The lack of capacity caused them much stress, living with multimorbidity requires adaptation to a stressful situation (Schulze et al. 2014). The high symptom burden made it difficult to make plans, and not being able to plan activities and socialize with friends made the participants feel isolated and lonely. Similar findings have been found in a study of older people with heart failure where the impact of unpredictable symptoms led to a rather isolated existence where they had to stay inside the house for most of the time (Aldred et al. 2005).

Symptoms limited several aspects of the participants' lives and unwillingly made them dependent on others for survival, and to be a burden made them feel guilty. These findings are in line with a study including older people suffering from heart failure. This study found that physical deterioration and increasing dependency was a major concern to the participants and to maintain control was of the highest importance (Waterworth and Jorgensen 2010). To feel like a burden to others has previously been shown to be associated with loss of dignity, depression and the will to live in older people near the end of life (Chochinov et al. 2005).

Living a daily life with a high symptom burden caused an emotional vulnerability. The participants described a burden of feeling sad, nervous, 
irritable and worried; feelings they usually could not understand or explain. The most vulnerable older people are often called "frail older people". Frailty is a multidimensional geriatric syndrome involving loss of reserves (energy, health, physical ability and cognition,) (Rockwood et al. 2005), and this could be a good description of the older people participating in this study. The participants said that living with a high symptom burden was very tiring; it was considered too big an effort to even try to do anything about their situation anymore. Lack of energy or fatigue have been shown to be highly prevalent symptoms among people with chronic diseases (Theander et al. 2014, Eckerblad et al. 2014); symptoms with an impact on both cognitive, physical and psychosocial functioning in the everyday lives of older people with heart failure and COPD (Theander and Unosson 2004, Aldred et al. 2005). Older people experiencing fatigue could also be at risk of suffering from depression (Hägglund et al. 2008).

The present study illustrates that living with a high symptom burden causes an unpredictability in daily life, since the burden of symptoms can quickly increase. However, managing all kinds of stressors or threats against health in old age requires personalized care and consideration of contextual factors, rather than merely treating one symptom or diagnosis at a time (Black et al. 2013). Older people with multi-morbidity are a complex and vulnerable group (Singer et al. 2011), with needs that are not met by our current health care system. These findings indicate that the symptom burden affects the whole life of these older 
people, and implementation of a holistic approach to determine both medical and psychosocial needs (Wieland 2003) might be beneficial, since it could lower the symptom burden. The participants included in this study had high prevalence of co-occurring symptoms as well as a high total symptom burden, which included both disease-specific and general symptoms. To reveal symptoms, health-care providers need to ask direct questions about symptoms. This is because older people attach great importance to not complaining and they do not like to bother others with their problems (Elias and Lowton 2014). Research has shown that symptoms tend to increase over time if not assessed and targeted for the right interventions, and if recognized, most symptoms can be treated (Walke et al. 2007).

\section{Strengths and Limitations}

One of the strengths of this study is the design, since there is a lack of research concerning older people's subjective descriptions of living with a high symptom burden related to multi-morbidity, especially when their illnesses have become more advanced. This group of people have previously often been excluded from research due to their frailty and having several interfering chronic diseases (Ritchie and Zulman 2013). To ensure trustworthiness, the concept credibility, conformability, dependability and transferability have to be taken into consideration (Graneheim and Lundman 2004), A few limitations need to be addressed. Some of the elderly people interviewed in this study were frail and 
sometimes had a hard time describing their situation. This may have compromised the quality of some of the interviews, causing them to have a shorter duration and less richness of data. All the participants in this study came from a similar background. Nevertheless, the findings ought to be transferable to similar groups in similar settings (Polit and Beck 2010).

\section{Conclusion.}

This study highlights the importance of a holistic approach when taking care of older people with multi-morbidity. This approach should employ a broad symptom assessment to reveal diseases and conditions that it is possible to treat or improve, and should challenge the ageist belief that old age causes illness. Symptoms should be communicated by health care providers, focusing on the total symptom experience and impact, taking both barriers as well as resources into consideration.

\section{Disclosures and Acknowledgments}

We hereby confirm that no conflicts of interest are associated with this publication and no significant financial support for these studies has influenced its outcome. Ethical approval has been obtained and this approval is acknowledged within the manuscript. The manuscript has been read and approved by all authors named therein. We especially thank the respondents in this study for sharing their experiences of living with a high symptom burden. 
Original funding was provided by the Faculty of Health sciences, Linkoping

University; the county council of Ostergotland; the Signe and Olof Wallenius

trust fund, and The Swedish Dementia Association. The funding sources were

independent and had no influence on the study.

\section{References}

Aldred, H., Gott, M. \& Gariballa, S. (2005) Advanced heart failure: impact on older patients and informal carers. Journal of Advanced Nursing, 49(2), 116124.

Bender, P. (1992) Eye on Elders: Deceptive Distress in the Elderly. The American Journal of Nursing Company, pp. 29.

Black, H.K., Santanello, H.R. \& Caruso, C.J. (2013) Managing threats against control in old age: a narrative inquiry. Nursing research, 62(6), 430-7.

Boeckxstaens, P. \& De Graaf, P. (2011) Primary care and care for older persons: position paper of the European Forum for Primary Care. Quality in primary care, 19(6), 369-89.

Cameron, J., Worrall-Carter, L., Page, K. \& Stewart, S. (2010) Self-care behaviours and heart failure: Does experience with symptoms really make a difference? European Journal of Cardiovascular Nursing, 9(2), 92-100.

Chochinov, H.M., Hack, T., Hassard, T., Kristjanson, L.J., McClement, S. \& Harlos, M. (2005) Understanding the will to live in patients nearing death. Psychosomatics, 46(1), 7-10.

Ebrahimi, Z., Wilhelmson, K., Eklund, K., Moore, C.D. \& Jakobsson, A. (2013) Health despite frailty: exploring influences on frail older adults' experiences of health. Geriatric Nursing, 34(4), 289-94.

Eckerblad, J., Theander, K., Ekdahl, A., Unosson, M., Wirehn, A., Milberg, A., Krevers, B. \& Jaarsma, T. (2015) Symptom burden in community-dwelling older people with multimorbidity: a cross-sectional study. BMC Geriatrics, $15(1), 1$.

Eckerblad, J., Todt, K., Jakobsson, P., Unosson, M., Skargren, E., Kentsson, M. \& Theander, K. (2014) Symptom burden in stable COPD patients with moderate or severe airflow limitation. Heart Lung, 43(4), 351-7.

Elias, T. \& Lowton, K. (2014) Do those over 80 years of age seek more or less medical help? A qualitative study of health and illness beliefs and behaviour of the oldest old. Sociology of health \& illness, 36(7), 970-85. 
Elo, S. \& Kyngas, H. (2008) The qualitative content analysis process. Journal of Advanced Nursing, 62(1), 107-15.

Falk, H., Ekman, I., Anderson, R., Fu, M. \& Granger, B. (2013) Older patients' experiences of heart failure-an integrative literature review. Journal of nursing scholarship, 45(3), 247-55.

Gapstur, R.L. (2007) Symptom burden: a concept analysis and implications for oncology nurses. Oncology nursing forum, 34(3), 673-80.

Gill, A., Chakraborty, A. \& Selby, D. (2012) What Is Symptom Burden: A qualitative exploration of patient definitions. Journal of Palliative Care, 28(2), 83-89.

Goldberg, R.J., Spencer, F.A., Szklo-Coxe, M., Tisminetzky, M., Yarzebski, J., Lessard, D., Gore, J.M. \& Gaasch, W. (2010) Symptom presentation in patients hospitalized with acute heart failure. Clinical cardiology, 33(6), E7380.

Graneheim, U.H. \& Lundman, B. (2004) Qualitative content analysis in nursing research: concepts, procedures and measures to achieve trustworthiness. Nurse education today, 24(2), 105-12.

Hsieh, H.F. \& Shannon, S.E. (2005) Three approaches to qualitative content analysis. Qualitative health research, 15(9), 1277-88.

Hägglund, L., Lundman, B. \& Boman, K. (2008) The experience of fatigue among elderly women with chronic heart failure. European Journal of Cardiovascular Nursing, 7(4), 290-295.

Larsson, K. \& Thorslund, M. (2006) Old people's health. Scandinavian Journal of Public Health, 34 (suppl 67), 185-98

Le Reste, J.Y., Nabbe, P., Manceau, B., Lygidakis, C., Doerr, C., Lingner, H., Czachowski, S., Munoz, M., Argyriadou, S., Claveria, A., Le Floch, B., Barais, M., Bower, P., Van Marwijk, H., Van Royen, P. \& Lietard, C. (2013) The European General Practice Research Network presents a comprehensive definition of multimorbidity in family medicine and long term care, following a systematic review of relevant literature. Journal of the American Medical Directors Association, 14(5), 319-25.

Mazya, A.L., Eckerblad, J., Jaarsma, T., Hellström, I., Krevers, B., Milberg, A., Unosson, M., Westöö, A. \& Ekdahl, A. (2013) The Ambulatory Geriatric Assessment-a Frailty Intervention Trial (AGe-FIT)-A randomised controlled trial aimed to prevent hospital readmissions and functional deterioration in high risk older adults: A study protocol. European Geriatric Medicine, 4(4), 242-247.

McEvoy, L. \& Duffy, A. (2008) Holistic practice-a concept analysis. Nurse education in practice, 8(6), 412-9.

Newcomb, P. (2010) Using Symptom Management Theory to Explain how Nurse Practitioners Care for Children with Asthma. Journal of Theory Construction E Testing, 14(2), 40-44. 
Polit, D. \& Beck, C. (2010) Nursing Research - Appraising Evidence for Nursing Practice, (7th ed.). Wolther Kluwer Health/Lippincott Williams \& Wilkins.

Portenoy, R.K., Thaler, H.T., Kornblith, A.B., Lepore, J.M., Friedlander-Klar, H., Kiyasu, E., Sobel, K., Coyle, N., Kemeny, N., Norton, L. \& et al. (1994) The Memorial Symptom Assessment Scale: an instrument for the evaluation of symptom prevalence, characteristics and distress. European Journal of Cancer, 30A(9), 1326-36.

Riegel, B., Dickson, V.V., Cameron, J., Johnson, J.C., Bunker, S., Page, K. \& Worrall-Carter, L. (2010) Symptom recognition in elders with heart failure. Journal of nursing scholarship, 42(1), 92-100.

Ritchie, C.S. \& Zulman, D.M. (2013) Research priorities in geriatric palliative care: multimorbidity. Journal of palliative medicine, 16(8), 843-7.

Rockwood, K., Song, X., MacKnight, C., Bergman, H., Hogan, D.B., McDowell, I. \& Mitnitski, A. (2005) A global clinical measure of fitness and frailty in elderly people. Canadian Medical Association journal, 173(5), 489-95.

Salanitro, A.H., Hovater, M., Hearld, K.R., Roth, D.L., Sawyer, P., Locher, J.L., Bodner, E., Brown, C.J., Allman, R.M. \& Ritchie, C.S. (2012) Symptom burden predicts hospitalization independent of comorbidity in community-dwelling older adults. Journal of the American Geriatrics Society, 60(9), 1632-7.

Schulze, T., Maercker, A. \& Horn, A.B. (2014) Mental health and multimorbidity: Psychosocial adjustment as an important process for quality of life. Gerontology, 60(3), 249-254.

Sheppard, K.D., Brown, C.J., Hearld, K.R., Roth, D.L., Sawyer, P., Locher, J.L., Allman, R.M. \& Ritchie, C.S. (2013) Symptom burden predicts nursing home admissions among older adults. Journal of pain and symptom management, 46(4), 591-7.

Singer, S.J., Burgers, J., Friedberg, M., Rosenthal, M.B., Leape, L. \& Schneider, E. (2011) Defining and measuring integrated patient care: promoting the next frontier in health care delivery. Medical care research and review, 68(1), 11227.

Stewart, T.L., Chipperfield, J.G., Perry, R.P. \& Weiner, B. (2012) Attributing illness to 'old age:' consequences of a self-directed stereotype for health and mortality. Psychology $\mathcal{E}$ health, 27(8), 881-97.

Theander, K., Hasselgren, M., Luhr, K., Eckerblad, J., Unosson, M. \& Karlsson, I. (2014) Symptoms and impact of symptoms on function and health in patients with chronic obstructive pulmonary disease and chronic heart failure in primary health care. International journal of chronic obstructive pulmonary disease, 9, 785-94.

Theander, K. \& Unosson, M. (2004) Fatigue in patients with chronic obstructive pulmonary disease. Journal of Advanced Nursing, 45(2), 172-177. 
Wajnberg, A., Ornstein, K., Zhang, M., Smith, K.L. \& Soriano, T. (2013) Symptom burden in chronically ill homebound individuals. Journal of the American Geriatrics Society, 61(1), 126-31.

Walke, L.M., Byers, A.L., McCorkle, R. \& Fried, T.R. (2006) Symptom assessment in community-dwelling older adults with advanced chronic disease. Journal of pain and symptom management, 31(1), 31-7.

Walke, L.M., Byers, A.L., Tinetti, M.E., Dubin, J.A., McCorkle, R. \& Fried, T.R. (2007) Range and severity of symptoms over time among older adults with chronic obstructive pulmonary disease and heart failure. Archives of Internal Medicine, 167(22), 2503-2508.

Waterworth, S. \& Jorgensen, D. (2010) It's not just about heart failure - voices of older people in transition to dependence and death. Health $\mathcal{E}$ Social Care in the Community, 18(2), 199-207.

Wieland, D. (2003) The effectiveness and costs of comprehensive geriatric evaluation and management. Critical reviews in oncology/hematology, 48(2), $227-237$.

Zambroski, C.H., Moser, D.K., Bhat, G. \& Ziegler, C. (2005) Impact of symptom prevalence and symptom burden on quality of life in patients with heart failure. European Journal of Cardiovascular Nursing, 4(3), 198-206. 
Table 1. Description of participating characteristics

\begin{tabular}{|c|c|c|c|c|c|c|c|}
\hline $\begin{array}{l}\text { Participant } \\
\text { No. }\end{array}$ & Age & Gender & Marital status & $\geq 1$ Diseases in ICD 10 Chapter & Prevalent Symptoms & $\begin{array}{l}\text { Total symptom } \\
\text { prevalence }\end{array}$ & $\begin{array}{l}\text { Total symptom } \\
\text { burden score }\end{array}$ \\
\hline 1 & 87 & $\mathrm{~F}$ & Widowed & 1, 2, 4, 8, 9, 13 & $\begin{array}{l}\text { Pain, Lack of energy, Feeling nervous, Dry mouth, Feeling drowsy, } \\
\text { Numbness/tingling in hands/feet, Difficulty sleeping, Feeling sad, } \\
\text { Worrying, Lack of appetite, Dizziness, Feeling irritable, Swelling of } \\
\text { arms or legs }\end{array}$ & 13 & 1,22 \\
\hline 2 & 89 & M & Married & $2,4,5,6,7,8,9,10,11,12,13$ & $\begin{array}{l}\text { Pain, Shortness of breath, Difficulty sleeping, Numbness/tingling in } \\
\text { hands/feet, Cough, Problems with sexual interest or activity }\end{array}$ & 6 & 0.50 \\
\hline 3 & 84 & $\mathrm{~F}$ & Widowed & $2,3,5,9,11,13$ & $\begin{array}{l}\text { Pain, Feeling nervous, Difficulty sleeping, Diarrhea, Sweats, Feeling } \\
\text { bloated }\end{array}$ & 6 & 0.48 \\
\hline 4 & 79 & $\mathrm{~F}$ & Widowed & $4,5,8,9,10,13$ & $\begin{array}{l}\text { Pain, lack of energy, Difficulty concentrating, Dry mouth, Feeling } \\
\text { drowsy, Difficulty sleeping, Feeling bloated, Problems with urination, } \\
\text { Feeling sad, Mouth sores, Constipation. }\end{array}$ & 11 & 0.91 \\
\hline 5 & 85 & $\mathrm{~F}$ & Widowed & $3,4,6,9,11,12,13$ & $\begin{array}{l}\text { Pain, lack of energy, Dry mouth, Feeling drowsy, Numbness/tingling in } \\
\text { hands/feet, Problems with urination, Swelling of arms or legs, Diarrhea }\end{array}$ & 9 & 0.92 \\
\hline 6 & 82 & $\mathrm{~F}$ & Divorced & $3,4,6,9,11,12,13$ & $\begin{array}{l}\text { Lack of energy, Dry mouth, Cough, Numbness/tingling in hands/feet, } \\
\text { Feeling bloated, Swelling of arms or legs, Lack of appetite, Shortness } \\
\text { of breath, Dizziness, Feeling irritable, Weight loss, "I don't feel like } \\
\text { myself" Changes in skin. }\end{array}$ & 13 & 0.80 \\
\hline 7 & 89 & M & Married & $3,6,7,8,9,11,13$ & $\begin{array}{l}\text { Pain, Lack of energy, Dry mouth, Feeling drowsy, Problems with } \\
\text { urination, Constipation, Swelling of arms or legs, Problems with sexual } \\
\text { interest or activity, "I don't feel like myself", Itching, Feeling irritable. }\end{array}$ & 12 & 0.99 \\
\hline
\end{tabular}


Pain, Lack of energy, Dry mouth, Feeling drowsy, Difficulty sleeping,

swallowing, Feeling bloated, Feeling nervous, Feeling irritable, Feeling

sad, "I don't feel like myself", Itching, Lack of appetite, Mouth sores,

Problems with sexual interest or activity, Problems with urination,

Shortness of breath, Swelling of arms or legs, Sweats, Weight loss,

\section{Worrying}

11

Widowed

$1,4,6,7,8,9.10,11,12,13$

Pain, Lack of energy, Dry mouth, Feeling drowsy, Cough, Difficulty sleeping, Dizziness, Problems with urination, Swelling of arms or legs. 


\section{ICD 10 Chapters; Diagnosis according to International Classification of Diseases:}

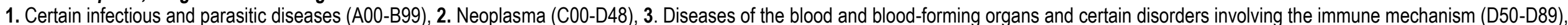

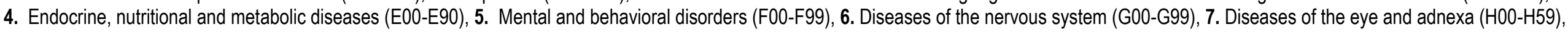

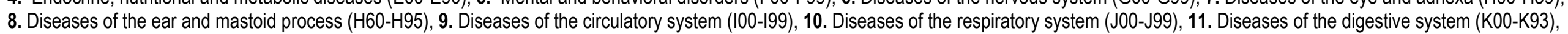

12. Diseases of the skin and subcutaneous tissue (L00-L99), 13. Diseases of the musculoskeletal system and connective tissue (M00-M99) 
Table 2: Example of the analytical process:

Meaning unit

$\begin{array}{lll}\text { Condensed } & \text { Sub-theme } & \text { Theme } \\ \text { transcription } & \end{array}$

Participant 15. I try and try, everyone says - you Don't have the To feel inadequate To adjust have to be more active, capacity to and limited or endure and I can do it, up to a certain point and then you are left there totally live up to expectations one's own or others'

empty. It's like the body

and mind are not

connected any more, It's

bloody awful actually

Examples of meaning units, from the analyses of total symptom burden in older people with multimorbidity 
To live with a high symptom burden

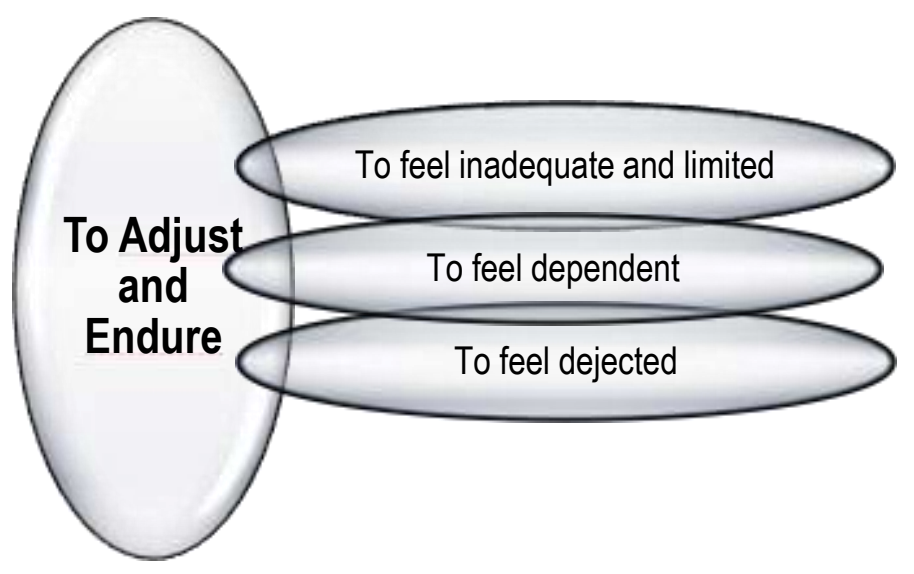

Fig 1. Theme and sub-themes of living with a high symptom burden. 